\section{Parental origin of the $\mathrm{X}$ chromosome in a patient with a Robertsonian translocation and Turner's syndrome}

\author{
M Krajinovic, K Ivanovic, L Mestroni, V Diklic, J Nikolis
}

\begin{abstract}
We report on a proband with both a Robertsonian translocation and Turner's syndrome. Study of the parental origin of the $X$ chromosome performed by microsatellite analysis indicates paternal origin of the $X$ chromosome (Xpat). The occurrence of chromosome aberrations as a consequence of interchromosomal interactions is discussed.
\end{abstract}

(f Med Genet 1994;31:255-256)

The occurrence of $\mathrm{X}$ chromosome monosomy and a Robertsonian translocation in the same person is rare. To our knowledge, there have been only two previous cases published. ${ }^{12}$ In both the Robertsonian translocation was familial and of $13 ; 14$ type.

The present report deals with a new case of monosomy $\mathrm{X}$ combined with $\mathrm{t}(13 ; 14)$. As the translocation was paternally inherited, we wanted to evaluate if the second aberration (XO) had the same origin.

Simple dinucleotide sequence repeats have been shown to be highly polymorphic and useful in genetic analysis since they are readily assayed by PCR. ${ }^{3}$ Therefore, we based our analysis on the microsatellite marker located at the extreme terminus of the dystrophin gene. ${ }^{4}$

The proband, a 16 year old girl, was admitted to hospital because of short stature and primary amenorrhoea. Physical examination showed phenotypic characteristics of Turner's syndrome: small mandible, epicanthic folds, hypertelorism, low set ears, short neck with pterigium and low $\mathrm{W}$ shaped posterior hair

International Centre for Genetic

Engineering and

Biotechnology

UNIDO, Padriciano

99, 34012 Trieste, Italy

M Krajinovic

L Mestroni

Department of

Pediatrics, General

Hospital, Pancevo,

Yugoslavia

K Ivanovic

Correspondence to

Dr Krajinovic.

Received 1 July 1993

Revised version accepted for

publication 24 September

1993 line, shield chest, undeveloped breasts with widely spaced hypoplastic nipples, cubitus valgus, short fourth and fifth metacarpals, short fifth finger with clinodactyly, and gonadal dysgenesis. Her intelligence was normal. At the time of birth her mother was 22 and her father was 23 years old. Her parents had a second daughter, six years younger and phenotypically normal. The mother had no history of spontaneous abortion and the father is a phenotypically normal male.

Chromosome analysis was performed on trypsin $\mathrm{G}$ banded chromosome preparations from peripheral lymphocyte cultures; 50 metaphases were scored.

Polymerase chain reaction was carried out on DNA extracted from blood samples. The oligonucleotides ${ }^{4}$ allowed the amplification of markers DYS1 and DYS111, with a size range of 177 to $185 \mathrm{bp}$ and 219 to $225 \mathrm{bp}$, respectively. Reactions and conditions of the amplification were as described by Feener et $a l^{4}$ and the PCR products were electrophoresed on a $5 \%$ non-denaturing polyacrylamide gel (figure A). The alleles of the marker were separated on a $10 \%$ non-denaturing polyacrylamide gel and visualised by ethidium bromide staining (figure B).

In the proband's lymphocytes, besides monosomy X, cytogenetic analysis showed the presence of a Robertsonian translocation: $44, X, t(13 q ; 14 q)$ (data not shown). The translocation chromosome was inherited from her father, whose karyotype was 45,XY,t(13q;14q). The karyotypes of her mother and sister were normal.

Amplification of the DYS1 marker was not informative in our family (data not shown).

B

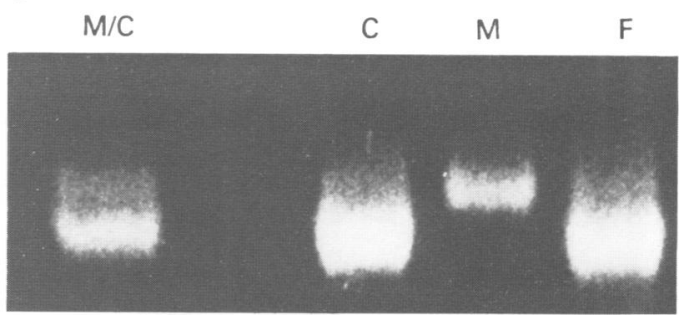

Detection of the DYS111 marker by gel electrophoresis after PCR. Amplified DNA of the father (F), mother (M), and child $(C)$ is indicated. Lane M/C has mixed PCR products of the mother's and child's DNA. Lane W is a DNA molecular weight marker VIII (Boehringer) with relevant fragments given in bp. 
However, PCR products of DYS111 clearly showed that the proband had inherited the paternal $\mathrm{X}$ chromosome, as they are both hemizygous for the same allele, while the mother is homozygous for the different marker allele (figure B).

The occurrence of two or more chromosome aberrations in the same person is presumed to be the result of an interchromosomal effect. There are reports of synaptic anomalies of other bivalents in the presence of a Robertsonian translocation, and also of associations between translocation trivalent and sex vesicle in the pachytene of Robertsonian translocation carriers. ${ }^{5}$ In the report of Salamanca et $a l^{2}$ the translocation $13 \mathrm{q} ; 14 \mathrm{q}$ of the patient was maternally inherited and the parental origin of the $\mathrm{X}$ chromosome could not be traced. Laszlo et al $^{1}$ concluded that there was no convincing evidence of an interchromosomal effect in the case of their patient.

The discovery of highly polymorphic PCR markers ${ }^{3}$ using specific $X$ linked oligonucleotides has made possible a new approach in the molecular diagnosis of Turner's syndrome, as well as the assignment of parental origin of the single $\mathrm{X}$ chromosome in affected subjects. Analysis of the parental origin of the retained $\mathrm{X}$ chromosome in our proband showed the presence of the paternal X (Xpat), indicating that the Robertsonian translocation has not influenced paternal gametogenesis. However, a Robertsonian translocation could influence non-disjunction in early embryogenesis.

Recent data ${ }^{6}$ support the hypothesis of Hook and Warburton ${ }^{7}$ that some degree of mosaicism is necessary for survival in early pregnancy. Even if a second cell line is not detected, its existence can not be excluded. ${ }^{6}$ We did not find any mosiacism in lymphocytes analysed both with cytogenetic and molecular techniques, and other tissues were not available for further investigation. The phenotype of our patient is typical of Turner's syndrome. However, because Xpat is inherited in $21 \%$ of $45, \mathrm{XO}$ conceptuses, ${ }^{8}$ as well as the finding that only about $20 \%$ of cases of Turner's syndrome are apparently non-mosaic, ${ }^{68}$ the loss of the Xmat chromosome during embryonic development seems to be more likely than nondisjunction in maternal meiosis.

We thank Dr Marion Cremer, University Institute for Human Genetics and Anthropology, Heidelberg, Germany, for kindly supplying us with the primers for amplificatin of the DYS 1 and DYS111 markers. We are grateful to Drs Vladimir Jurukovski and Julija Filipovska for DNA extraction.

1 Laszlo J, Bosce P, Gaal M, Toth A. A case of $44, \mathrm{X}$ streak gonad syndrome combined with familial balanced 13/14 translocation. Acta Med Hung 1984;41:223-7.

2 Salamanca F, Buentello L, Sanchez J, Armendares S. A patient with 44 chromosomes. Ann Genet (Paris) 1985;28:130-2.

3 Weber JL, May PE. Abundant class of human DNA polymorphisms which can be typed using the polymerase chain reaction. Am $\mathcal{f}$ Hum Genet 1989;44:388-96.

4 Feener CA, Boyce FM, Kunkel LM. Rapid detection of CA polymorphisms in cloned DNA: application to the 5 region of the dystrophin gene. Am $f$ : region of the

5 Navarro J, Vidal F, Benet J, Templado C, Marina S, Egozcue J. XY trivalent association and synaptic anomalies in a male carrier of a Robertsonian $t(13 ; 14)$ translocation. Hum Reprod 1991;3:376-81.

6 Held KR, Kerber S, Kaminsky E, Singh S, Seemanova E Goedde HW. Mosaicism in 45, X Turner syndrome: does
HWh survival in early pregnancy depend on the presence of two sex chromosomes? Hum Genet 1992;88:288-94.

7 Hook EB, Warburton D. The distribution of chromosomal genotypes and evidence for diminished fetal mortality and severity in genotypes associated with structural $\mathrm{X}$ abnormalities or mosaicism. Hum Genet 1983;64:24-7.

8 Hassold T, Pettay D, Robinson A, Uchida I. Molecular studies of parental origin and mosaicism in $45, \mathrm{X}$ conceptuses. Hum Genet 1992;89:647-52. 